\title{
"SUMAR Y NO SER SUMADOS": CULTURAS JUVENILES REVOLUCIONARIAS. MAYO DE 1968 Y DIVERSIFICACIÓN IDENTITARIA EN CHILE $^{1}$
}

"To add but not to be added": Youth cultures Revolutionaries. May 1968 and identitary diversification in Chile

"Fue la rebelión de un segmento de la clase media y fue una verdadera 'revolución cultural', en el sentido en que no lo fue la China (...). Las generaciones anteriores habían conocido el culto al padre terrible, adorado y temido: Stalin, Hitler, Churchill, De Gaulle. En la década de los 60 una figura ambigua, alternativamente colérica y orgiástica, los Hijos, desplazó a la del Padre saturnino. Pasamos de la glorificación del viejo solitario a la exaltación de la tribu juvenil”.

Octavio Paz.

\section{Resumen}

El trabajo analiza y discute la génesis y diversificación identitaria de las y los jóvenes en Chile a partir de su articulación y secularización con los movimientos estudiantiles. Para ello se centra en algunos referentes que posibilitaron la emergencia de la juventud como sujeto y actor social, para llegar a la expansión y diversificación de las culturas juveniles en sincronía tanto con los procesos de reforma universitaria en el país (1967) como con el imaginario emancipatorio y juvenilizante emanado de la revolución de mayo de 1968 en Francia.

Palabras clave: Juventud chilena, historia de las culturas juveniles, culturas juveniles revolucionarias, mayo de 1968, Movimiento de Izquierda Revolucionaria.

\section{Abstract}

This paper analyzes and discusses the genesis and the identity diversification of Chilean youth, starting from their articulation and secularization with regard to the student movements. In order to do so, it is centered in some referents that made possible the emergency of youth as subject and social actor, so as to arrive to the expansion and diversification of youth cultures in synchrony with the Chilean university reform (1967), and with the emancipationist and juvenilized imaginary that came along with the French revolution of May 68'.

Key words: Chilean youth, history of youth cultures, youth cultures revolutionaries; may 1968; Revolutionary Left Movement.

${ }^{1}$ Este trabajo forma parte del proyecto Fondecyt $N^{\circ} 11075007$. Una versión preliminar fue expuesta en el Congreso "1968 en Amèrique: émergence de nouveax acteurs". Centre de Recherches Ibériques et Ibéro-Américaines. Université de Paris 10, Nanterre (mayo 29 del 2008. 


\section{Yanko González}

\section{MAYO ANTES DE MAYO}

¿Cómo se vincula, se intersecta o se superpone el mayo de 1968 francés con los "mayos" sudamericanos y, particularmente, con el chileno? Las memorias - esas políticas del presente- siguen en conflicto para leer el estallido francés ya como un nodo nutricio y axial del "sistema interconectado central" de la emancipación juvenil o bien, como un relámpago solitario en el temporal generativo de la adolescencia global y la juventud autoconsciente. La pugna entraña reflexividad histórica y espacial: para qué y por qué pensar nuestros mayos latinoamericanos desde la interconexión con los mayos metropolitanos, si nos sobran las deudas con el grito insurreccional de Córdoba, ese mayo de 1968 materializado 50 años antes —en 1918 — por los estudiantes radicales de esta universidad argentina. ¿No es el mayo francés un Cordobazo tardío? ¿No es la aparición de la universidad libre, obrera y popular argentina, chilena o peruana a principios del siglo pasado, una simiente augural - o inflexión temprana - de la reforma educacional de la década del sesenta en gran parte de Europa? ¿No fue el rostro "adulescente" - adulto perpetuado en adolescente- del Che el que inspiraba el camino insurreccional propio? ¿No se concretó en la Nicaragua Sandinista, con "la revolución de los muchachos", la comunión obrera, campesina y de sobremanera juvenil (Cfr. Lutte, 1979) que en la incipiente revolución de mayo del 68' quedó segada?

Estas interrogantes y asertos se vienen repitiendo en Sudamérica desde hace décadas, teñidas de un particularismo paralizador - "Escaramuzas como las de mayo 68 se realizan cada fin de mes en las capitales de América Latina...", diría Montiel en los 80' (1986:128) —; o de una parcialidad retrospectiva, que se proyecta hoy de la mano del historiador chileno Claudio Rolle "Se trata una vez más del poder de los lugares. (...) la revolución, una moda que se impone en la capital de la moda. (...) su impacto será mucho más duradero en el plano mítico que en el político, social y económico" (La Tercera, sábado 10 de mayo, 2008), o de Nicolás Casullo, autor de Paris 68, las escrituras, el recuerdo (1998): “QQué le podía decir el estudiante francés a un universitario chileno de izquierda en 1969 (...)?. Fue al revés: cuando yo estuve en París en aquel 68' lo único que se veían eran imágenes y rostros de Guevara, Castro, Mao, Ho Chi Minh, Lumumba. Sobre Europa influían los "arrabales de Occidente" de donde nacería la revolución que el centro del capitalismo no había podido realizar" (Diario El Mercurio, 13 de abril de 2008).

Curiosamente, lo que habilita a Montiel, Casullo, Rolle - y por cierto al que suscribe - para hablar de Guevara, Castro o los "arrabales de Occidente", es este mayo (re)inicial de Nanterre que en su operatoria "patrimonial" ha

visibilizado y revitalizado mayos geográfica y temporalmente distantes que la 
memoria urde y recrea para afirmar la singularidad en medio de la homogeneización globalizadora, la sanción o el control del recuerdo. Por lo mismo, renunciar a la agonística de las memorias desplegadas en la diversidad geocultural, la horizontalidad o verticalidad temporal, es perder un mayo, quizás, el más fecundo y pertinaz de los pocos que nos quedan en la contemporaneidad.

Conexiones biyectivas o unidireccionales, descargas atomizadas o circuitos eslabonados, lo cierto es que pensar la especificidad de los mayos no nos debe conducir necesariamente a la parálisis comprensiva, más bien retroalimenta su potencial heurístico. Tras el decorado, el escenario y el poliédrico guión revolucionario de los muchos mayos - de Córdoba a Brighton, de San Francisco a Praga, de México a Berkeley, de Concepción a Roma-- quedan sin maquillaje sus actores: juventudes que eclosionaron y que ensancharon los intersticios institucionales desmantelando frontalmente el adultocentrismo y la dependencia social de las y los jóvenes para fundirse y reconocerse en una simultaneidad espacio-temporal, en una épica "sincrónica diacrónica".

Si el mayo parisino es estructurado o estructurante del légamo de muchas de las emancipaciones regionales o continentales a fines de la década del 60' (desde las subjetivizantes, a las capitalistas, coloniales, imperialistas, stalinistas o de género), no es lo central si nos guiamos por el imaginario que irradia y re-instala: una radical emancipación de la edad como dato y corsé biológico, a la edad como atalaya sociocultural liberadora. Un movimiento de compresión histórica que sintetiza en un mes - amplificado por las citadas "sincronías diacrónicas" - varias décadas en la dialéctica de las identidades juveniles en buena parte de Occidente. Compresión que recorre, primero, la génesis de la juventud como actor social "privilegiado", cuya condición sólo alcanza a los sectores elíticos, ilustrados y masculinos articulados en torno a distintas adscripciones generacionales, desde "conexiones generacionales" a "unidades generacionales autoconscientes" (Manheim, 1993), para llegar a democratizarse progresivamente alcanzando a sectores populares y subalternos, en una cadena de procesos --muchos de ellos recursivos y no necesariamente lineales y acumulativos- que amplían la visibilidad del sujeto juvenil y explican la diversificación exponencial de éste con la aparición de las "culturas juveniles" vía la industria cultural y los medios de comunicación de masas satelizados bajo el lente aumentado de los varios mayos de la década de los 60'.

El concepto de "cultura juvenil" resulta cardinal para entender los mayos de la década del 60', debido a que encierra una diversidad de respuestas simbólicas y estructurales (de clase, género, territoriales y culturales, entre otras), donde las experiencias sociales de las y los jóvenes 


\section{Yanko González}

son expresadas colectivamente mediante la construcción de estilos de vida distintivos, localizados fundamentalmente en los espacios insterticiales de la vida institucional. "Microsociedades" con grados significativos de autonomía de las sociedades adultas que se dotan de espacios y tiempos específicos (Feixa, 1999). La categoría evidencia el paso —en palabras de Margaret Mead (1977) — de una cultura "posfigurativa" y "cofigurativa" a una "prefigurativa" en la que los pares - las y los jóvenes-- reemplazan a los adultos como referentes para la construcción del presente sociocultural, instaurando una ruptura en el entramado de las "clases de edad" sin parangón en buena parte del siglo XX occidental.

Desde este punto de vista, los atributos conectivos del mayo francés son fundamentalmente juvenilizantes, razón por la cual se desdibuja el dilema - aunque no la pugna-- sobre su "influencia" o "insularidad" en la escucha latinoamericana. Grito o eco, esa muesca en la cara de De Gaulle con las palabras "Sé Joven y Cállate" reverbera en la casa mental de Chile e interpela gran parte del canto de su historicidad.

¿OLVIDAR 1918? ¿OLVIDAR 1925? ¿OLVIDAR $1938 ?$

Por mucho tiempo, las todavía escasas investigaciones socio-históricas acerca del transcurso de las identidades juveniles en América Latina tendían a reiterar la idea de una corporeización "real" de los colectivos juveniles con la expansión social de la educación y el desarrollo de la industria cultural, logrado en propiedad sólo a partir de la década de 1950. Antes de estos procesos, se insistía, existían "jóvenes sin juventud".

Por el contrario, sostenemos que en nuestra región, particularmente en el Cono Sur, algunos mayos antes de mayo dejaron una secuela "radiactiva juvenilizante" similar al parisino. El movimiento insurreccional de los estudiantes de Córdoba en 1918 no sólo trajo consigo la modificación de la estructura "monástica y clerical" en su organización universitaria (logrando el co-gobierno estudiantil, la autonomía universitaria, el derecho de asociación, la injerencia en los contenidos académicos y el acceso de las clases populares a la enseñanza superior), sino que sintetizó la mutación de la "juventud biológica" a una "juventud sociocultural", que deviene por vez primera en nuevo actor social (González, 2002). Más allá de su configuración identitariajuvenil (mayoritariamente ilustrados —estudiantes - mesocráticos y masculinos), las conexiones o "simultaneidades" de su emergencia en América Latina son múltiples.

Al menos en Chile, se expresa en la articulación de la Federación de los Estudiantes de Chile - FECH, "el kindergarten de los terroristas", según una expresión de la época por su conformación mayoritariamente ácrata- con las vanguardias políticas y sociales y un emergente proletariado urbano. Ésta 
protagonizó masivas protestas y movilizaciones populares durante gran parte de las primeras décadas del siglo pasado. Su cenit será la presentación de un candidato presidencial propio - Vicente Huidobro- el 17 de octubre de 1925 por la "Convención de la Juventud Chilena", conformada mayoritariamente por estudiantes fogueados en las revueltas universitarias y obreras. El poeta había llegado de Francia después de haber trabado amistad con las vanguardias artísticas. Tenía a su haber un conjunto de obras en francés - se ganaría el mote de "poeta francés nacido en Chile" (Rojas, 2001:213) — y un creciente prestigio internacional. Huidobro se lanza a la carrera presidencial en medio de una debacle institucional provocada por la renuncia temporal del presidente Arturo Alessandri. En agosto de 1925 funda y dirige Acción. Diario de Purificación Nacional donde escribe la arenga ¡Balance Patriótico!, que resume con magistral vehemencia su enfática y violenta reivindicación generacional, capitalizando el largo mayo chileno que fue el de los primeros años de la década del veinte

(...) El país no tiene más confianza en los viejos, no queremos nada con ellos. Entre ellos, el que no se ha vendido, está esperando que se lo compren. (...) Entre la vieja y la nueva generación, la lucha va a empeñarse sin cuartel. (...). Que los viejos se vayan a sus casas, no quieran que un día los jóvenes los echen al cementerio. Todo lo grande que se ha hecho en América y sobre todo en Chile, lo han hecho los jóvenes. Así es que pueden reírse de la juventud. Bolívar actuó a los 29 años. Carrera, a los 22; O’Higgins, a los 34 (...) (Huidobro, 1925a).

Los sectores estudiantiles ven en la candidatura del vate la encarnación de sus intereses como sujetos juveniles, los que Huidobro con 33 años - "adulescente" tardío- anima y amplía. En el afiche propagandístico de su candidatura se lee: "Vote por Vicente Huidobro Candidato de la Juventud. Semanas antes, en una carta dirigida a la Federación de Estudiantes aceptando su candidatura, Huidobro le daría nombradía a los nuevos actores. ${ }^{2}$ Una ampliación e incipiente diversificación interna de los actores juveniles tendrá lugar a principios de la década del 30', provocada por el advenimiento de ideologías que encauzan y suman reivindicaciones propiamente generacionales en otras de mayor rango. De esta forma, a través de la apropiación de estos discursos ideológicos (marxista y nacionalista, fundamentalmente), se articulará una reivindicación

\footnotetext{
2 “(...) Jóvenes, seamos jóvenes, seamos dinámicos, seamos enérgicos, seamos puros, desinteresados y dispuestos al sacrificio. Sacudamos esta apatía de buey durmiente que adormece hasta el paisaje de primavera con su sola presencia. (...) si realmente he logrado sacudir el adormecimiento de siesta española que nos caracteriza, podré volver a Europa pensando que valía la pena haber venido a la patria, pues he realizado en ella algo grande. ¡Hicimos nacer la juventud!”, Huidobro (1925b).
} 


\section{Yanko González}

pro-generacional juvenil, como el caso de las Milicias Socialistas, la Falange Nacional y, particularmente, el Movimiento Nacional Socialista Chileno. Este movimiento protagonizará "la matanza del seguro obrero", rebelión e intento de golpe de Estado llevado a cabo en 1938 por 59 jóvenes nacistas "a la criolla" los que serán asesinados por las Fuerzas Armadas mandatadas por el presidente Arturo Alessandri para sofocar la revuelta. La particularidad es que este camino conduce a sectores de clases medias y populares a visualizarse como actores juveniles en el seno de las juventudes políticas emergentes, operando la partidización — militancia y militarización — como motor fundamental de producción de "juventud" (González, 2004b). ${ }^{3}$ Militancia y militarización que en la década de los 60' será un factor exponencial para la tribalización de muchos de estos colectivos expresados en la emergencia de las llamadas "juventudes revolucionarias" (Goecke, 1997) o —como planteamos aquí- de "culturas juveniles revolucionarias".

\section{LA "PATRIA JOVEN"}

Las condiciones de producción de las culturas juveniles chilenas están marcadas por la paulatina modernización de la esfera material que, sustentada en gran medida por el Estado Desarrollista y Populista y el éxito económico norteamericano después de la Segunda Guerra Mundial - traspasado a América Latina vía la "Alianza para el Progreso" - posibilitarán la extensión de la electricidad, la urbanización, la expansión de la matrícula educativa, la industrialización y la migración campo-ciudad. ${ }^{4}$

Sobre la modernización material se impone la "modernización" de la esfera simbólica, conducida en gran medida por la aparición y extensión de los medios de comunicación de masas y la industria cultural segmentada. Cambios que, ciertamente, son tributarios de la transnacionalización del mercado simbólico en América Latina y la reproducción de la industria

\footnotetext{
${ }^{3}$ Un testimonio ejemplar de este momento lo refiere Luis Galdames, dirigente de la Fech para entonces: “(...) Al iniciarse la década de los 40', la juventud universitaria presentaba el espectáculo de un cuadro multicolor. Era la época de los uniformes y por las calles marchaban las "camisas pardas" de acero y blancas, según fuera el partido a que cada joven perteneciera" (1985:18).

4 Desde mediados de siglo, la sociedad chilena venía sumando cambios acelerados, que terminaron por modificar radicalmente su estructura social. Se manifestaba un sostenido crecimiento demográfico debido a un aumento de la natalidad y esperanza de vida y una baja de la mortalidad. Así comienza a emerger una mayoría "biológicamente" joven: sólo al comenzar la década del 60' el 49,4\% de la población era menor de 20 años, según cálculos de la CEPAL/UNICEF en 1967 (Gurrieri, et al., 1971:17). Junto a ello, se manifiesta a partir de 1952 un incremento sin parangón del estudiantado secundario y superior ( $C f r$. Salazar y Pinto 2002). En efecto, el número de alumnos universitarios que en el año 1952 era de 9.335, para 1957 esta cantidad sube a 20.440 y en 1965 a 41.801 (González, 2004a).
} 
cultural del primer mundo a nivel local. En este sentido, la llamada "Sociedad de la abundancia" norteamericana impactó radicalmente la vida social y al sujeto joven de la región a partir de la década de los 50': surgimiento de un inédito mercado juvenil masivo (teenager market): periodismo juvenil, industria musical segmentada (el Rock and Roll irrumpe con toda su fuerza) junto con toda una serie de productos asociados, desde transistores, discos y tocadiscos, películas, motocicletas, hasta objetos fetiches de diverso tipo. La personificación de este momento se encuentra en el surgimiento de varios ídolos musicales y cinematográficos, cuyas imágenes se transnacionalizan rápidamente a partir de las tecnologías comunicativas recién estrenadas: Elvis Presley, James Dean y Marlon Brando, encarnaciones matrices de las culturas juveniles en EE.UU. Estas se manifiestan progresivamente en Chile desde la formación de los fans clubs y gruppies, hasta las pandillas juveniles imitadoras de sus héroes musicales y de película, tipo El Salvaje (dirigida por Laszlo Bebedek y protagonizada Marlon Brando en 1954), y Rebelde sin causa (cinta dirigida por Nicholas Ray, en 1955, y con James Dean como protagonista). "La edad de moda" — en el decir de Aranguren (1961) — alcanza rápidamente a Europa a través de la modernización y el "bienestar" generado desde 1947 por el European Recovery Programm, conocido como "Plan Marshall". Allí comienzan a generarse fenómenos similares, personificados — avanzada la década del 60' - en el grupo musical “The Beatles" y en las nacientes culturas juveniles modeladoras en Inglaterra, Francia e Italia: Teddy Boys, Blousson Noirs, Vitelloni, Raggare, Hippies, etc. ${ }^{5}$

Por otra parte, la llegada del gobierno demo-cristiano de Eduardo Frei en 1964 y su "Revolución en Libertad" se sostuvo en una estrategia comunicativa que no sólo propició las reformas sociales y económicas que se hacían urgentes para esos años (como la reforma agraria), sino que se caracterizó por la cooptación de las energías juveniles (básicamente estudiantiles) reflejada vivamente en uno de sus lemas de campaña: "La patria joven". ${ }^{6}$ Más allá de

\footnotetext{
${ }^{5}$ En este sentido Carles Feixa (1999:43-44) plantea que son cinco las condiciones, antes inexistentes, que provocan la emergencia de las primeras culturas juveniles. El autor sostiene que se asocian al Estado de Bienestar (ocio y un poder adquisitivo mayor por parte de los jóvenes); la pérdida de autoridad paterna, la modernización de las "costumbres", en cuanto a una erosión de la moral puritana que desembocó en un consumismo creciente y la "revolución sexual", cuyos portadores fueron esencialmente los jóvenes; y finalmente dos procesos capitales: tanto la expansión de los medios de comunicación de masas que, según el autor, creó una verdadera cultura popular juvenil internacional, y la creación de un teenage market, como espacio de consumo diferenciado y productor de una identidad juvenil más masificada.

${ }^{6}$ No es del todo azaroso que a mitad de la década de los 60' la Juventud Demócrata Cristiana - y sus orgánicas aliadas como la AUC (Acción Católica Universitaria), la JOC (Juventud Obrera Católica) y posteriormente tanto la JEC (Juventud Estudiantil Católica) como el movimiento en torno a la llamada "Iglesia Joven"- domine la mayor parte de los centros de
} 


\section{Yanko González}

los discursos del dirigente estudiantil de la Universidad Católica, Miguel Ángel Solar Silva - llamado en cierta memoria colectiva el "Cohn Bendit chileno"- exigiendo frente al rector que la universidad "cambie sus viejas estructuras y los hombres que la sostienen, para que se coloque al servicio de su pueblo (...)" (Discurso íntegro en Cifuentes, 1997:231) el inicio del movimiento reformista tuvo un impacto estructural menor, en la medida que desafiaba sólo en tono moral a la propia clase de la cual estos sujetos eran hijos: elites y mesocracias engendradas en el catolicismo conservador. La sujeción a esta clase les impidió, más allá de los discursos, pasar de las reivindicaciones educativas sectoriales a las de más amplio rango.

De ahí que los procesos de reforma universitaria llevados a cabo en Chile desde sus inicios en 1967 hasta su sedimentación en los primeros años de 1970, no iluminen cabalmente los vasos comunicantes — por la vía de los estallidos juvenilizantes - en la región y el resto del mundo. Aunque la "plataforma demográfica estudiantil" sostiene su accionar, son los grupos secularizados discursiva y empíricamente de las instituciones educativas las que sintetizan una alteración en las trayectorias de las identidades juveniles, que son capaces - como en París - de pasar fugaz o sistemáticamente de las reivindicaciones del co-gobierno universitario a la destrucción o toma del poder; de la rabia sectorial a la "revuelta popular". ?

En los primeros años de 1960, la industrial cultural y los medios de comunicación de masas en Chile ya habían creado un teenage market sustentado en un poder adquisitivo mayor por parte de los jóvenes. Este espacio de consumo diferenciado extendió tanto el imaginario como la

alumnos de educación secundaria y universitaria. Estas orgánicas gatillarán los procesos de reforma universitaria en 1967. Consecuentemente, ésta no se genera en las universidades del Estado, sino en las universidades privadas ligadas a la iglesia Católica, como la Universidad Católica de Valparaíso y, posteriormente, la UC de Chile en Santiago. Sus demandas — anacrónicas en contraste con las de Córdoba - surgen como un alegato incontenible frente a la asfixia clerical y autárquica del catolicismo universitario. En medio de la toma de la Universidad Católica de Santiago, se instaló una "bofetada" lírica que simbolizó el proceso de reforma: un gran lienzo colgado bajo la estatua de Cristo con los brazos abiertos, que rezaba "El Mercurio Miente", haciendo alusión al periódico de derecha de más larga data en Chile y que había descalificado en sus páginas las movilizaciones reformistas.

${ }^{7}$ En este sentido, no son los grupos de presión gremial-estudiantil, ni los universitarios per-se los que modulan y articulan los movimientos emancipatorios con otros similares en el mundo, sino la retroalimentación y maridaje identitario entre la condición juvenil, adquirida ya sea por su posición estructural de estudiantes o consumidores/productores de bienes simbólicos segmentados, y la condición de "revolucionarios/as", soportado en la militancia y en la militarización pro-generacional. Un conjunto indisoluble que da a luz una verdadera microcultura, homologable a las que en ese momento histórico habían aparecido fruto sólo de la industria cultural angloamericana (rockanrroleros, nuevaoleros, carlotos, coléricos —en Chile_; bloussons noirs — en Francia_-; rockers, mods —en Inglaterra--, entre otras). 
experimentación de una identidad juvenil en vastos sectores sociales (sellos discográficos como Rca-Victor, DICAP, Deamon, revistas juveniles como Rincón Juvenil, Ritmo, Ramona, o programas radiales como Discomanía, contribuyeron notablemente a este proceso). La moda se convierte en un espacio preponderante de diferenciación generacional, de allí que tanto el blue jeans como la minifalda se conviertan en "lengua franca" de adscripción juvenil, es decir, en "sustratos juveniles desterritorializados" (Muñoz, 1998:264). Bajo estas y otras manifestaciones públicas se esconden múltiples alteraciones en la vida cotidiana debido a la modernización de las "costumbres", como la erosión de la moral conservadora, la crisis de la autoridad paterna, la separación de la genitalidad con la procreación - de la mano de los anticonceptivos- y de sobremanera, la instalación desde 1959 — con la revolución cubana - de una narrativa enquistada en el cambio social violento: el ser revolucionario como modo contemporáneo de ser joven. Es el caso de pequeñas orgánicas como la llamada "Tendencia Disidente" escindida de las Juventudes Comunistas en 1968; el MR-2 -Movimiento Revolucionario Manuel Rodríguez- (nacido en 1969), el MAPU — escindido de la Democracia Cristina - y, fundamentalmente, como veremos, el Movimiento de Izquierda Revolucionaria, MIR.

\section{DE LENNON A LENIN}

Andrés Pascal, uno de los fundadores del MIR, relata que en medio de la visita de Fidel Castro a Chile en 1971, el presidente Salvador Allende invitó a Miguel Enríquez, Secretario General del MIR, a reunirse con el comandante cubano. Castro insistía en la relevancia de la unidad de la izquierda y la importancia de que el MIR se sumase oficialmente a la Unidad Popular, el conglomerado de partidos políticos que sustentaba al gobierno de Allende. En la ocasión, Fidel sermonea al líder del MIR, diciéndole "el arte de la revolución es el arte de sumar fuerzas... sumar... sumar... y sumar". A lo que Enríquez contesta: "Sí, comandante, es el arte de sumar y no ser sumados". (Punto Final, 22 de septiembre de 2000).

¿Cómo se explica esta respuesta algo irreverente del jovencísimo Miguel Enríquez a Fidel Castro, uno de los mentores y paradigmas ideológicos del propio MIR?

El MIR, por sus características constitutivas (escisión de las juventudes dependientes de partidos "adultos", llamados por ellos "izquierda tradicional"), es un ejemplo paradigmático de estas "(sub)culturas revolucionarias". En este sentido, y siguiendo a Feuer (citado en Auth y Joannon, 1985) este desgajamiento de los partidos tradicionales de izquierda aparece como un rechazo generacional al padre colectivo representado por el "Partido", el que emana de una crítica radical en nombre de los principios vulnerados por la política de las generaciones precedentes. 


\section{Yanko González}

El nacimiento de la orgánica (Cfr. Enríquez, 1971, Sandoval, 1990; Naranjo, 1999; Pascal Allende, 2000-2001) es fruto de la confluencia de distintos grupos marxistas, ácratas, trotskistas y pro chinos que formarán en 1962 la "Vanguardia Revolucionaria Marxista", a la que se sumarán jóvenes estudiantes de la Universidad de Concepción escindidos de la Federación Juvenil Socialista y de las Juventudes Comunistas. Después de este intento de aglutinación, se sufre otra escisión que terminará saldándose con la creación del MIR, el 15 de agosto de 1965, cuya propuesta diferencial —en relación a la izquierda histórica y la ruta asumida por la Unidad Popular liderada por Allende - pasa por adscribirse, desde una vanguardia "autoasignada", a la teoría táctico-militar guevarista del "foco revolucionario"; la llamada "revolución permanente" en contraposición al "etapismo"; la crítica radical al "socialismo burocrático" stalinista y el apoyo a los postulados de Fidel Castro y Mao Tse Tung en torno a una opción "tercermundista" de la Revolución (Cfr. M.I.R. "Declaración de Principios...", 1965). ${ }^{8}$

El MIR logra tener un arrastre importantísimo en la Universidad de Concepción - epicentro de su génesis - consiguiendo la expulsión de la ciudad del Cuerpo de Paz norteamericano; echando del barrio universitario a Robert Kennedy, hermano del presidente de Estados Unidos; llegando a la presidencia de la Federación de Estudiantes de Concepción en 1967 con Luciano Cruz, y protagonizando acciones armadas de "recuperación" en entidades bancarias. A poco andar, la orgánica se desplaza de las aulas universitarias creando para ello distintos "Frentes de Masas", como el MCR (Movimiento Campesino Revolucionario), el MPR (Movimiento de Pobladores Revolucionarios) y los GPM (Grupos Políticos-militares). La mayoría de estos frentes están constituidos por cuadros jóvenes que se entronizan en las bases sociales

\footnotetext{
8 Pese a que, en un primer momento, la formación del movimiento tendrá un cariz medianamente intergeneracional, el MIR se reordenará organizativa, ideológica y tácticamente en 1967, alejando del movimiento y del propio Comité Central a los miembros - todos mayores, como el legendario líder sindical Clotario Blest- que no creerán o no pondrán en práctica la "insurrección armada" en contra de la "legalidad burguesa" para la consecución del socialismo. Así, el MIR es finalmente liderado por jóvenes autodenominados los "no tradicionales" que controlan la mayoría del Comité Central y la totalidad del Secretariado General, pasando a cristalizar el prototipo identitario que se fijará en el imaginario colectivo: su constitución y "poder" juvenilizante. Andrés Pascal, miembro de la dirigencia, atestigua este proceso: “(...) La nueva generación mirista nos volcamos (sic), con el entusiasmo de los jóvenes, a prepararnos para la lucha armada, impulsar la movilización estudiantil, vincularnos a las organizaciones sociales populares, y ganar más jóvenes para la causa revolucionaria (...). Después de dos años de la fundación del MIR, esta nueva generación constituía la mayoría absoluta de la organización, pudiendo elegir en el congreso de 1967 al grueso de los miembros del Comité Central y a Miguel (Enríquez) como Secretario General. (Revista Punto Final, 11 de agosto de 2000).
} 
subalternas (campesinos y pobladores fundamentalmente), para propiciar la lucha armada. Así, el movimiento es el puntal de una vanguardia que intenta transformar las meras luchas reformistas universitarias, en luchas revolucionarias de largo alcance.

La no participación del MIR en la coalición de partidos del gobierno de la Unidad Popular (Comunista, Socialista, Radical, entre otros), no es sólo la pertinacia de una autonomía por las diferencias en las "vías" al socialismo y sus críticas al electoralismo, el stalinismo, la invasión a Checoslovaquia o el conflicto chino-soviético, sino una distancia asentada en enclaves generacionales ligados a la acentuación de una "identidad generacional autoconsciente" ( $C f r$. Mannheim, op. cit.) por parte de los miembros del MIR y por extensión, las culturas juveniles revolucionarias. Básicamente se oponen a la instrumentalización de sus energías, estrategias y cuadros por parte de partidos concebidos como "retaguardias adultas". La autoconciencia generacional da paso a una verdadera cultura juvenil cuando se resiste a la domesticación y dependencia orgánica e ideológica, en franca oposición al mundo adulto, "electoralista", "etapista" y "transaccional". 9"

Todo lo anterior implica no sólo distinciones y distancias intergeneracionales, sino intrageneracionales — con sus propios pares, "reaccionarios" o "reformistas", por ejemplo- que convierten a la orgánica y su "periferia" en una verdadera microcultura juvenil. En torno al estilo expresado en un conjunto más o menos coherente de elementos materiales e inmateriales (Feixa, 2004) las y los jóvenes "revolucionarios" escenificaban su alteridad tribalizada. Dicho estilo, de hecho, se corporeizará en las cinco dimensiones constitutivas básicas de toda cultura juvenil a partir de la segunda mitad del siglo XX:

A) Un lenguaje propio. Desde el término "fierro" para referirse a las armas de fuego, "tareas especiales" o "recuperación" para aludir a las acciones armadas, hasta los resemantizados conceptos de "cuadro", como agente calificado en labores de dirección, o el extendido "compañero", para referirse en forma vicaria al correligionario como a la pareja sentimental. Palabras, entonaciones, giros, frases hechas y lemas que prestados de sociolectos anteriores enfatizan su posición generacional: "avanzar sin tranzar" o "nuestro compromiso es con la revolución, el partido es sólo un instrumento" (Martínez, 63).

B) Música. Las culturas juveniles revolucionarias crearon un nuevo imaginario simbólico anti-imperialista que apela y rescata lo local alimentándose de la vía propia -latinoamericana y nacional— al socialismo: la llamada "Nueva Canción Chilena",

\footnotetext{
${ }^{9}$ Esto, por cierto, la distingue —en la dialéctica de las identidades juveniles en Chile- con colectivos de similar naturaleza, claramente ejemplificado en la relación entre la dirigencia nacista y su "Jefe" —González Von Marees— y los jóvenes del Movimiento Nacional Socialista Chileno.
} 


\section{Yanko González}

con Víctor Jara, Inti Illimani, Quilapayún, entre muchos otros. ${ }^{10}$ Quizás sean Quilapayún (militantes del MIR primero y después de las Juventudes Comunistas) junto a Víctor Jara (también militante comunista), los artistas que representen más vivamente la cultura juvenil revolucionaria de ese entonces. La distinción con respecto a otros ejes aglutinadores de identidad juvenil fueron rápidamente denunciados moral y políticamente por estos autores, como intentos de invasión cultural y propaganda por parte de Estados Unidos del american way of life, que provocaba alienación y desclasamiento en la juventud. ${ }^{11}$ Así, se convirtieron en fuertes críticos de las "imitaciones chilenas" de esas culturas juveniles y su medios, como la propia revista Ritmo de la Juventud. En este contexto, una de las canciones menos conocidas de Víctor Jara escrita en 1969. “¿Quién mató a Carmencita?”, aborda con bastante claridad los elementos fundantes y constitutivos del joven revolucionario desde su opuesto, aquel que vive con el peso de la influencia de ser joven bajo las señales del imperialismo y el capitalismo. La canción, según Joan Jara, se basa en una historia real: la de una muchacha que se suicidó bajo la influencia de las drogas y "que vivía en el mismo barrio sórdido en que Víctor había crecido" (Jara, 1999:171). ${ }^{12}$ La audición y la producción musical serán elementos centrales, hasta

\footnotetext{
${ }^{10}$ Este movimiento será la simiente y síntoma visible de la configuración de una cultura juvenil que emplazará y combatirá a otras, ligadas a la industrial cultural nacional y transnacional, como la Nueva Ola: Peter Rock, Cecilia, el Pollo Fuentes, entre otros; el Neofolklore o la Sicodelia (Los Vidrios Quebrados, Los Jaivas, y otros), utilizando para ello la plataforma juvenilizante de la naciente industria cultural partidaria y estatal (el sello discográfico DICAP, las radios, revistas y festivales). Este movimiento musical y cultural ha sido ampliamente estudiado (Torres, 1980; Salas, 2003; Rolle, González, Ohlsen, 2009). El proceso de transición a la irrupción definitiva de la Nueva Canción a nivel musical se denominó "Neofolklore" que, a semejanza de los movimientos musicales argentinos de la época (sobre todo Los Chalchaleros, Atahualpa Yupanqui, Eduardo Falú, entre otros, que se habían desarrollado bajo el "auspicio legal" de Perón) es el primer síntoma de una reacción a la música rock y pop extranjera. Esta reactividad del Neofolklore más que política fue culturalmente esencialista, ya que a partir del rescate de las "tradiciones patrias" - el folklore canonizado— se estiliza y juveniliza. El Neofolklore abre el camino del mercado musical a otras tendencias discriminadas por la industria y el mercado (fundamentalmente Rolando Alarcón y Patricio Manns) que co-habitan, en un primer momento, con el Neoflolklore y que, a la larga, se convertirán en corrientes opuestas al canto engolado y un tanto espurio de éste, sumando al acervo folklórico un repertorio latinoamericanista e internacionalista vinculado a proyectos emancipadores (canciones republicanas de la guerra civil española).

${ }^{11}$ El Documental Descomedidos y Chascones (1972) de Carlos Flores, resulta axial en este sentido, al dar voz a un grupo heterogéneo de jóvenes, donde las opiniones críticas y radicales en relación a la juventud alienada por el "imperialismo" son subrayadas textual y visualmente por Flores.

${ }^{12}$ Parte de la canción expresa: (...) "Apenas quince años y su vida marchita.// E1 hogar le aplastaba y el colegio aburría. // En pasillos de radios su corazón latía // deslumbrando sus ojos los ídolos del día.// Los fríos traficantes de sueños en revistas // que de la juventud engordan y profitan // torcieron sus anhelos y le dieron mentira // la dicha embotellada, amor y fantasía. // (...) La muchacha ignoraba que la envenenarían, // que toda aquella fábula no le pertenecía, // conocer ese mundo de marihuana y piscina, // con Braniff International viajar a la alegría. // (...)" (Jara, 1970).
} 
decantarse en verdaderos himnos de la identidad ("En la lucha contamos las horas, ya a los ricos les llega su fin, porque estamos seguros de triunfar con el pueblo, conciencia y fusil. MIR, MIR, MIR").

C) Estética. Así como el tupé y la chaqueta negra de los rockers, los trajes a medida de los mods, los vestidos floreados y las melenas de los hippies, o los alfileres $\mathrm{y}$ mohicanos de los punks, las culturas juveniles revolucionarias patentaron un repertorio creativo que para el caso del MIR funcionará a través de un mecanismo también clásico: la reapropiación y resemantización objetual que los singulariza. Tal como el vestido eduardiano de los teddy boys (apropiado de los dandies durante el reinado del Rey Eduardo), el look mirista juvenil masculino podía incluir "una parka azul petróleo clara (...), camisa sport y pantalones de cotelé, hasta el denominado 'uniforme azul': un chaquetón largo de ese color muy similar al que usaban los marinos" (Minay, 2007:22). Una melena bajo control, cuellos de tortuga, patillas y barbas combinan con los bototos y el "verde oliva" de marcado acento militar. El uso, por parte de las muchachas, de pantalones, zapatos planos o botas, suéteres ajustados al cuerpo y boinas, les dan un cariz unisex inevitablemente insurreccional. Por otra parte, muchos de ellos adoptaron, tal como en la década de 1930, los "uniformes" partidarios (las Juventudes Comunistas, por ejemplo, cambiaron su uniforme blanco y pañuelo rojo que era imitación de los "pioneros" soviéticos, por la camisa de color amaranto) y desfilaron bajo "un bosque de banderas, rojas, verdes, azules, rojinegras" (Ramona, 17 diciembre de 1971). Especulando una escenificación de aquella imagen, Eduardo Carrasco ha confesado: "nuestro sueño más secreto de aquella época era algo así como caer heridos, envueltos en los jirones de las banderas revolucionarias, delante de una tribuna de espectadores (...)" (1988:123).

D) Producciones Culturales. Al consumo de bienes simbólicos segmentados, lo acompaña su revés, la producción de una serie de documentos, revistas, afiches, declaraciones, graffitis, murales, lienzos, etc., cuya función interna es reafirmar las fronteras de grupo y, externa, promover el diálogo con otras instancias sociales y juveniles para transformar el estigma en emblema. En este sentido, muchas pugnas intelectuales entre las y los jóvenes pertenecientes al "horizonte juvenil revolucionario" constituyen una rica producción cultural de orden discursivo. En Entre Lenin y Lennon. La militancia juvenil de los años 60 (1996), un pequeño libro de memorias, Sergio Martínez — anónimo militante miembro de Tendencia Disidente- relata cómo al estilo de los "cristianos fundamentalistas que citan los versículos de la biblia", los jóvenes militantes se intercambiaban citas de Marx, Engels o Lenin. Martínez recuerda que el texto preferido con que los jóvenes comunistas desacreditaban a los miembros del MIR, era $E l$ izquierdismo, enfermedad infantil del comunismo, de V. I. Lenin. A su vez, los miristas, replicaban con El Estado y la Revolución del mismo Lenin. Disputas que llegaron a provocar distancias insalvables entre los Jóvenes Comunistas y Miristas, en un clima donde estos últimos le reprochaban al PC su complicidad "partidaria" en Bolivia por la muerte del Che Guevara.

E) Actividades focales. La identificación subcultural se concreta en la participación en determinados rituales y actividades focales propias. La asistencia a marchas, sitting, tomas, asambleas, expropiaciones y acciones de "recuperación"; determinados locus de sociabilidad, desde las "Peñas" — lugares de esparcimiento, 


\section{Yanko González}

consumo musical y de debate intelectual que habían "importado" de Francia Violeta, Isabel y Angel Parra - hasta a la clandestinidad o el "trabajo de masas" configurarán "una comunidad ideológica y existencial", como expresará Max Marambio el ex militante y jefe del GAP. Este proceso pertinaz de autonomía liga en "sincroníadiacrónica" al MIR a muchos movimientos y orgánicas revolucionarias fraguadas al calor de la juvenilización francesa. La propia trayectoria de la trotskista Juventud Comunista Revolucionaria escindida del Partido Comunista Francés; o la maoísta Unión de Juventudes Comunistas Marxista Leninista (UJC-ML) y una serie orgánicas menores atomizadas - como el propio Movimiento 22 de Marzo- de origen ácrata y situacionista, se emparentan microculturalmente con un segmento importante de las juventudes revolucionarias, que tienen en el MIR su expresión paradigmática. Así, el mayo parisino será un "referente de simultaneidad" en relación al MIR y su accionar. El disciplinamiento sovietizante del PC, como la ambigüedad guevarista y marxistaleninista del PS, es el rostro del conservadurismo revolucionario adulto al que el MIR se opone. La emergencia de un movimiento alternativo a la izquierda tradicional de corte eminentemente juvenilizante no había tenido presencia en la historia de Chile y el MIR lo sabe. En medio de las tomas de la Universidad de Concepción, en 1968, y aprovechando la gratuidad telefónica, uno de los hermanos de Andrés Pascal enviaba desde París largas horas de reportes políticos sobre las revueltas y barricadas (Comunicación Personal de “A. S.”). Claramente, al Movimiento le seducía la imagen de la épica revolucionaria conducida y embanderada por una joven, en la medida que anticipaba la meta simbólica del "otro socialismo".

Si en Francia el estallido de estas culturas juveniles revolucionarias son doblegadas vía el entendimiento de los sindicatos, el Partido Comunista Francés y el gobierno de De Gaulle, en Chile tendrán su pequeña gran victoria con el triunfo de la Unidad Popular. Las propias relaciones de Salvador Allende con el MIR reflejan los espacios que gana el movimiento al interior de la izquierda institucionalizada: un adulto comprensivo (Allende) con respecto a los jóvenes "rebeldes". Dichas relaciones intergeneracionales son por momentos centrales. Relevante resulta la formación de la guardia de seguridad de Allende, el GAP (Grupo de Amigos Personales), integrado, en una primera etapa, por jóvenes del MIR. Del mismo modo, el indulto de Allende a varios miembros del Movimiento por procesos judiciales en su contra (acciones armadas). Igualmente, el ofrecimiento de Allende a Miguel Enríquez de integrarse como Ministro de Salud al gobierno (tal como lo había sido él, cuando joven, en el gobierno del Frente Popular con Aguirre Cerda). Los gestos de Allende se suman y representan, quizás, el "triunfo juvenilizante y revolucionario" del MIR al interior de la sociedad chilena y de la izquierda. Uno fundamental y público será el discurso del mandatario en la Universidad de Guadalajara. Allí se ve compelido a responder a esos autónomos y juvenilizantes proto-guerrilleros reconociendo el peso de los acontecimientos 
(...) Ser joven y no ser revolucionario es una contradicción hasta biológica, pero ir avanzando en los caminos de la vida y mantenerse como revolucionario en una sociedad burguesa es difícil. Cómo no requerir precisamente capacidad y capacitación a los revolucionarios, por lo tanto, el dirigente político universitario tendrá más autoridad moral si acaso es también un buen estudiante universitario. Ser agitador universitario y mal estudiante es fácil, ser dirigente revolucionario y buen estudiante es más difícil, pero el maestro universitario respeta, al buen alumno y tendrá que respetar sus ideas cualesquiera que sean $(. ..){ }^{13}$

En la misma dirección transitan sus gestos íntimos, como lo relata Andrés Pascal, sobrino del presidente: “(...) Salvador Allende, mi tío, me hizo llegar una caja de zapatos. Al abrirla, encontré una pistola Colt 45 , nuevecita, y una nota que decía: Tú escogiste ese camino. Sé consecuente con él". (Punto Final, 25 de agosto de 2000). ${ }^{14}$

\section{CODA TENTATIVA}

En suma, si hay una "sincronía-diacrónica" entre los varios mayos del 60' — particularmente el de París y el chileno - ésta será representada no por la juvenilización vía la estudiantilización, como ocurrió en los años 20' del siglo pasado en el Cono Sur latinoamericano, sino por un proceso sociocultural transversal que interpela a un horizonte de culturas juveniles particulares (las revolucionarias) y a (sub)culturas juveniles específicas, que condensan las conexiones más ilustrativas en cuanto a su separación y autonomía con respecto a los "mayores", expresados en la crítica radical y violenta a toda fórmula "adultamente transitada" para llegar al socialismo. La configuración de una verdadera cultura juvenil revolucionaria tuvo su clímax en las postrimerías de la década de los 60' y cuyo fin "parcial" fue el golpe de Estado de 1973. La originalidad de esta conformación cultural reside en que el "mercado" y la propia industria cultural dominante, no tuvieron el papel central de articulación sino, más bien, los partidos políticos y, en menor medida, la industria cultural estatal (sobre todo bajo la U.P.) que, sumada a una precaria industria cultural independiente y subterránea, fue capaz de sobreponerse a la irradiación mediática de las imágenes dominantes de la juventud del momento

\footnotetext{
${ }^{13}$ Transcripción nuestra del discurso ofrecido en el auditorio del Instituto de Ciencias Sociales y Humanidades - hoy auditorio Salvador Allende- de la Universidad de Guadalajara, el 2 de diciembre de 1972. Una versión fragmentada de este discurso en Latorre (1974:185).

${ }^{14}$ Como sabemos, bajo el lema "el MIR no se asila", el movimiento se declara la única orgánica que decide resistir militarmente a la dictadura inmediatamente después del 11 de septiembre. Razón por la cual la mayor parte de sus militantes son asesinados, ejecutados o están desaparecidos.
} 


\section{Yanko González}

(abundantes testimonios de esta situación la confieren los propios productores culturales involucrados, de allí la creación de la DICAP).

La supresión de esta cultural juvenil por el golpe Militar fue parcial porque ese mismo imaginario impregnó fuertemente — desde principios de la década de los 80 ' - a los "hijos" de esta generación, que en el combate contra la dictadura pinochetista, con los partidos de izquierda en la clandestinidad y bajo la influencia de las luchas revolucionarias y de resistencia sandinista en Nicaragua, ${ }^{15}$ le dieron continuidad, con una fuerte carga de mitificación de lo que habían sido en la década del 60'. Esta diversificación de las juventudes revolucionarias tendrá, no obstante, algunos rasgos diferenciales, como es su vínculo con la irrupción de nuevos actores juveniles, la llamada "juventud urbano-popular", que complejiza y diversifica identitariamente en mayor grado a estos colectivos en Chile.

\section{Universidad Austral de Chile* Instituto de Ciencias Sociales Casilla 567, Valdivia (Chile) ygonzale@uach.cl}

\section{BIBLIOGRAFÍA}

AUTH, J.; JOANNON, F. "El movimieno estudiantil: Un marco conceptual", en Garretón, M. A. \& Martínez, J. (Eds). Universidades Chilenas, Historia, Reforma e Intervención. La biblioteca del movimiento estudiantil. Tomo IV. Santiago: Sur, 1985.

CARRASCO, Eduardo. Quilapayún. La revolución y las estrellas. Santiago: Ornitorrinco, 1988.

CASULLO, Nicolás. "La revolución domesticada", en Diario El Mercurio, Suplemento Artes y Letras, 13 de abril. 2008:E2-E3.

ENRÍQUEZ, M. "Algunos antecedentes del Movimiento de Izquierda Revolucionaria (MIR)". Reproducción del documento interno hecho en Chillán por el Centro de Estudios Miguel Enríquez. Chillán: CEME, 1971.

FEIXA, Carles (coord.); PORZIO, Laura; GUTIÉRREZ, Israel. BORDONADA, Mireia. Culturas Juveniles en España (1960-2004). Madrid: INJUVE, 2004.

- De Jóvenes, Bandas y Tribus. Barcelona: Ariel, 1999.

FLORES, Carlos. Descomedidos y Chascones. Santiago: Cine Experimental Universidad de Chile, 1972.

\footnotetext{
${ }^{15}$ Particularmente, esta lucha revolucionaria se convirtió, en la década de los 80', en el eje revitalizador principal de esta cultura juvenil, básicamente porque los protagonistas de esos procesos eran jóvenes que pertenecían a una misma "conexión generacional" con aquellos. En un original estudio sobre la revolución sandinista y los jóvenes, Lutte (1979) llama a ésta la "revolución de los muchachos". Una gráfica fuente de estas coordenadas de adscripción identitaria se encuentra en el libro-testimonio del combatiente sandinista Omar Cabezas. La Montaña es algo más que una inmensa estepa verde (1997). México: Siglo XXI. (Orig. 1982).
} 
HUIDOBRO, V. "Balance Patriótico". Diario Acción, 6 de agosto. 1925a:1-2.

----- "Carta de Vicente Huidobro", en Revista Espiga. Quillota, 1925b:3. También, en www.uchile.cl/cultura/huidobro (visitada: 05/12/2008).

JARA, Joan. Víctor Jara, un canto truncado. Barcelona: B, 1997.

JARA, Víctor. “¿Quien Mató a Carmencitos?”, en Álbum Canto Libre. Santiago: EMIODEON, 1970.

GONZÁLEZ, Yanko. "Que los Viejos se Vayan a Sus Casas. Juventud y Vanguardia en América Latina", en Movimientos Juveniles. De la globalización a la antiglobalización. Feixa, C.; Costa, C.; Saura, J. R. (Eds.). Barcelona: Ariel, 2002:59-91.

"Óxidos de identidad: Memoria y juventud rural en el sur de Chile (1935-2003)". Tesis Doctoral Inédita. Universidad Autónoma de Barcelona, 2004a.

"Existieron una vez sesenta y dos muchachos: Paramilitarización y militancia de las juventudes mesocráticas chilenas", en JOVENes, Revista de Estudios sobre Juventud. México DF: Nº 19, 2004b:82-115.

GALDAMES, Luis. "Percepciones Generacionales", en La Juventud frente al Futuro de Chile. Santiago: CINDE, 1985.

GOECKE, Ximena. "Nuestra Sierra es la Elección. Juventudes Revolucionarias Chilenas (1964-1973). Tesis Licenciatura en Historia, Pontificia Universidad Católica de Chile, 1997.

GURRIERI, A.; Torres-Rivas, E., et al. Estudios sobre la juventud marginal latinoamericana. México: Siglo XXI, /Editorial Universitaria, 1971.

LATORRE, H. El pensamiento de Salvador Allende. México: F. C. E., 1974.

LUTTE, G. Il n'y a plus d'adolescence! Les jeunes au Nicaragua. París: Les Éditions Ouvriéres, 1979.

MANNHEIM, Karl. "El Problema de las generaciones", en Revista Española de Investigaciones Sociológicas. No 62, abril-junio. Madrid: 1993:62-93.

MARAMBIO, Max. Las armas de ayer. Santiago: La Tercera-Debate, 2007.

MARTÍNEZ, Sergio. Entre Lenin y Lennon. La militancia juvenil de los años 60. Santiago: Mosquito Comunicaciones, 1996.

MEAD, Margaret. Cultura y Compromiso. Barcelona: Gedisa, 1990.

MINAY, S. "Las huellas del MIR en Goñi”, en Revista Qué Pasa Nº 1879, 13 de abril. Santiago, 2007:22-23.

M.I.R. (Movimiento de Izquierda Revolucionaria). Declaración de Principios. Santiago: S/E, 1995.

MONTIEL. Edgard. "Participación juvenil en la sociedad y la política", en Revista de Estudios sobre Juventud $\mathrm{N}^{\circ}$ 20. Madrid: 1986:125-146.

MUÑOZ, Germán. "Identidades culturales e imaginarios colectivos. Las culturas juveniles urbanas vistas desde la cultura del rock", en Martín-Barbero, J. y López de la Roche, F. (Eds.). Culturas, Medios y Sociedad. Bogotá: Universidad Mayor de Colombia, 1998.

NARANJO, P. Biografía de Miguel Enríquez. Chillán: Centro de Estudios Miguel Enríquez, CEME, 1999.

PASCAL ALLENDE, Andrés. "El MIR, 35 años", en Revista Punto Final, 11 de agosto. Santiago: 2000. 


\section{Yanko González}

"El MIR, 35 años. Un atajo revolucionario, Parte II", en Revista Punto Final, 25 de agosto. Santiago: 2000.

------- “El MIR, 35 años. Un período pre-revolucionario, Parte III”, en Revista Punto Final, 8 de septiembre. Santiago: 2000.

------ "El MIR, 35 años. El fin de la UP, Parte IV", en Revista Punto Final 25 de septiembre. Santiago: 2000.

------ 'El MIR, 35 años. El fin de la UP, se desata la guerra contra el pueblo, Parte V”, en Revista Punto Final, 20 de octubre. Santiago: 2000.

RAMONA (Revista). "iiiLa juventud de pie!!! Muralla contra el fascismo”. 17 de diciembre. Santiago: 1971.

ROJAS, Waldo. Poesía y Cultura Poética en Chile. Aportes Críticos. Santiago: Universidad de Santiago de Chile, 2001.

ROLLE, Claudio. "Modelo 68", en Diario La Tercera. Suplemento Cultura, 2008:4-5.

ROLLE, Claudio; GONZÁLEZ, Juan Pablo; OHLSEN, Óscar. Historia Social de la Música Popular en Chile: 1950-1970. Santiago: Universidad Católica de Chile, 2009.

SALAS, Fabio. La Primavera Terrestre. Cartografía del rock chileno y la Nueva Canción Chilena. Santiago: Cuarto Propio, 2003.

SAlAZAR, G.; PINTO, J. Historia Contemporánea de Chile. Tomo V: Niñez y juventud. Santiago: LOM, 2002.

SANDOVAL, C. MIR (Una Historia). Santiago: Sociedad Editorial Trabajadores, 1990.

TORRES, Rodrigo. Perfil de la Nueva Canción Chilena desde sus orígenes hasta 1973. Santiago: Ceneca, 1980. 